\title{
An individualized fMRI-based protocol to assess semantic memory in a heterogeneous multilingual population
}

\author{
Magali Perquin ${ }^{a b^{*}}$, Shivakumar Viswanathan ${ }^{b}$, Michel Vaillant ${ }^{c}$, Okka Risius $^{\text {bf1 }}$, \\ Laetitia Huiarta ${ }^{\mathrm{a}}$, Jean-Claude Schmit ${ }^{\mathrm{d} 2}$, Nico J. Diederiche ${ }^{\mathrm{e}}$ Gereon R. Fink ${ }^{\text {bf }}$, Juraj Kukolja ${ }^{\text {bfgh3 }}$ \\ aLuxembourg Institute of Health, Department of Population Health, Strassen, Luxembourg \\ ${ }^{b}$ Cognitive Neuroscience, Institute of Neuroscience and Medicine (INM-3), Forschungszentrum Jülich, \\ Jülich, Germany \\ cLuxembourg Institute of Health, Competence Center for Methodology and Statistics, Strassen, \\ Luxembourg \\ dLuxembourg Institute of Health, Strassen, Luxembourg \\ eCentre Hospitalier de Luxembourg, Department of Neurology, Luxembourg-City, Luxembourg \\ tDepartment of Neurology, Faculty of Medicine and University Hospital Cologne, University of Cologne \\ gHelios University Hospital Wuppertal, Department of Neurology and Clinical Neurophysiology, \\ Wuppertal, Germany \\ hWitten/Herdecke University, Faculty of Health, 58448 Witten, Germany
}

\section{Abstract}

The cognitive stimulation induced by multilingualism may slow down age-related memory impairment. However, a suitable neuroscientific framework to assess the influence of multilingualism on age-related memory processes is missing. We propose an experimental paradigm that assesses semantic memory processes using functional magnetic resonance imaging (fMRI). To this end, we modified the picture-word interference (PWI) task to be suitable for multilingual subjects undergoing functional magnetic resonance imaging (fMRI). In particular, stimulus material was prepared in multiple languages and closely matched in semantic properties, thus enabling participants to perform the experiment in a language of their choice. This paradigm was validated in a group $(n=62)$ of healthy elderly ( $\geq 64$ years) multilingual subjects, all practicing three or more languages. Consistent with the engagement of semantic memory processes, we found that the encoding and recognition of semantically related vs. unrelated picture-word pairs evoked robust differences in behavior and the neural activity of parietal-temporal networks. These effects were not modulated by the

Present addresses:

${ }^{1}$ Center of Mental Health, Marienheide, Germany

2Directorate of Health, Ministry of Health, Luxembourg

${ }^{3}$ Department of Neurology and Clinical Neurophysiology, Helios University Hospital Wuppertal, Wuppertal, Germany; Faculty of Health, Witten/Herdecke University, Witten, Germany

"Corresponding author: Luxembourg Institute of Health, Department of Population Health, 1A-B, rue

Thomas Edison, L-1445 Strassen, Luxembourg; E-mail address: magali.perquin@lih.lu 
language in which the task was performed. Based on this validation in a multilingual population, we conclude that the proposed paradigm will allow future studies to evaluate whether multilingualism aptitude engages neural systems in a manner that protects long-term memory from aging-related decline.

Keywords: fMRI, multilingualism, public health, picture word interference task, aging, memory decline 


\section{Introduction}

In the aging population, neurodegenerative dementias are an increasing medical and socioeconomic problem. Since effective therapies are lacking, targeting the modifiable determinants of these dementias may be the key to future strategies to prevent cognitive decline. Stimulating cognitive activities are an essential part of this toolkit (Baldivia, Andrade, \& Bueno, 2008; Williams, Pendleton, \& Chandola, 2020). The increased cognitive demands of practicing two or more languages (i.e., multilingualism) has been identified as a factor that could reduce the occurrence of memory impairment and dementia (Bialystok, Craik, \& Freedman, 2007; Perquin et al., 2013). Current evidence for this protective role of multilingualism is based on neuropsychological assessments. However, the neural mechanisms by which multilingualism modulates age-related memory processes remain poorly understood. This gap is also methodological since prior studies have focused on the demands that multilingualism places on executive control processes rather than memory (Abutalebi et al., 2012; Dash, Berroir, Joanette, \& Ansaldo, 2019; Kousaie \& Phillips, 2012). We sought to address this methodological shortcoming in the current study. We present a semantic memory task specifically developed to investigate memory-related neural processes in an aging multilingual population using functional magnetic resonance imaging (fMRI). Notably, the task specifically engages language-independent aspects of memory (i.e., semantics) triggered by language-specific stimuli (i.e., words).

Semantic context can exert a powerful influence on memory. The congruency of scenes, objects, or events can elicit an amplified neural response (Packard et al., 2017) and produce multiple behavioral effects such as an increase in the speed and accuracy of recognition while also increasing false recall (Crafa, Hawco, \& Brodeur, 2017; Flegal, Marin-Gutierrez, Ragland, \& Ranganath, 2014; Packard et al., 2017). However, another critical approach to study semantic contextualization specifically involving words is with "Stroop-like" paradigms (Starreveld \& La Heij, 2017). In the original Stroop task (Stroop, 1935), the ink color of a displayed word (e.g., ROOM) has to be reported (e.g., blue) while ignoring the meaning of the word. Despite this instruction, there is a relative slowing of responses when the ink color and the meaning of a word are incongruent (e.g., RED). This delayed response suggests a conflict between the correct response ('blue') and the competing response ('red') triggered by the automatic processing of the word's meaning. The picture-word interference (PWI) effect (Rosinski, 1977) is particularly relevant here. This phenomenon occurs in a 
Stroop-like task where the object displayed in a picture must be named while ignoring a simultaneously displayed distractor word. In this task, the time to name the visually depicted object (e.g., sofa) is increased by a distractor word describing a semantically related object (e.g., chair) (La Heij, 1988; Starreveld \& La Heij, 2017).

Multilingualism has been shown to modulate the PWI effect because the task involves word retrieval in one language but the simultaneous inhibition of competing words of the same meaning in other languages (Ehri \& Ryan, 1980; Friesen, ChungFat-Yim, \& Bialystok, 2016). We sought to engage the contextualization processes identified by the PWI phenomenon but with one crucial difference: in our modified task, participants were instructed to explicitly identify a semantic relationship between the displayed picture and word, rather than ignoring the distractor word, like in typical PWI paradigms. We consider this adapted paradigm to be better suited for studying memory-related processes in aging populations rather than a paradigm requiring information to be ignored. Indeed, recent findings have shown that, relative to younger adults, older adults memorize more irrelevant distracting information irrespective of their semantic relevance (Amer, Ngo, Weeks, \& Hasher, 2020).

Finally, a key challenge is the use of language materials with multilingual participants. One strategy to deal with a high linguistic diversity has been to use nonlanguage materials (Abutalebi et al., 2012; Dash et al., 2019; Kousaie \& Phillips, 2012). However, we reasoned that language materials would be more valuable to trigger the effects of multilingualism on cognition (Canini et al., 2016) and semantic memory. Nonetheless, an experimental protocol that uses written materials in only one language is inadequate since it requires participants to use a non-proficient language. It also excludes participants with a preference for another language. In order to address these biases, the experimental task used here was personalized such that the language of the word stimuli used for each participant was based on their self-reported preference (Figure 1A). A fundamental assumption to be validated by the study is that the task engages similar neural processes/mechanisms irrespective of the language of the stimulus materials.

In summary, we developed a semantic memory paradigm with individually customized language stimuli that allows task performance in the language chosen by the participant. With this paradigm, our validation focused on addressing two central questions: (1) Does the semantic contextualization during encoding affect memory and 
bioRxiv preprint doi: https://doi.org/10.1101/2021.09.07.459272; this version posted September 8, 2021. The copyright holder for this preprint (which was not certified by peer review) is the author/funder, who has granted bioRxiv a license to display the preprint in perpetuity. It is made available under aCC-BY-NC 4.0 International license.

its underlying brain activity? (2) Are the semantic memory effects on the associated networks modulated by the chosen language? 


\section{Methods}

\section{Population}

Sixty-two participants (mean age $70 \pm 5.7$ years; 36 females) completed all stages of the study protocol as part of the MEMOLINGUA study (N'REC-CESP-20141124). They were recruited using a press release. There was no financial compensation for participation. To be included in the study, participants had to be older than 64y, right-handed (self-reported), have normal or corrected-to-normal vision, have no history of psychiatric and neurological disorders, and be free of contraindications for MRI scanning. All participants were multilingual (minimum number of languages: 3 ) and had a score $\geq 25$ (mean: 28.8, SD: 1.23) in the Mini-Mental-StateExamination (MMSE) (Folstein, 1983). Furthermore, an essential consideration for our experimental protocol was to ensure that all participants were from a common socio-cultural context. Therefore, only participants living in Luxembourg were included rather than a mixture of participants from neighboring countries such as Belgium, France, or Germany (where the scanning was performed).

The study involved two independent (non-sequential) parts that were separately conducted at the Department of Population Health, Luxembourg Institute of Health (LIH) and the Institute of Neuroscience and Medicine (INM-3), Research Center Jülich (Germany), respectively. In one part, detailed epidemiological information about each participant (e.g., demographics, neuropsychology, medical history, socio-cultural background, linguistic ability) was acquired over multiple (2 to 4 ) interviews conducted in Luxembourg (either at the $\mathrm{LIH}$ or the participant's residence). This assessment followed the procedure previously described in Perquin et al. (2012) and will be presented in a separate paper. In the second part, participants were transported to (and from) the Institute for Neuroscience and Medicine, Research Centre Jülich, for a single-day MRI session. The mean time to complete all parts of the study was 1.8 months. The study protocol was approved by the National Ethics Committee for Research (CNER, N²01501/03). Participants provided their signed informed consent for the entire study at $\mathrm{LIH}$ and for the MRI session at the Research Center Jülich.

\section{Stimulus materials}

Participants selected their preferred language for the stimuli to be presented during the experiment. The four available language options were Luxembourgish, French, German, and English. For each participant, the complete stimulus set across all experimental conditions consisted of 96 pictures and 256 visually depicted words in the selected language (see Supplementary materials).

The picture stimuli were naturalistic color photographs depicting every-day, easily nameable objects that were either natural (e.g., fruits, animals) or synthetic/artificial (e.g., tools, clothes). Pictures were selected from normed databases (Brady, Konkle, Alvarez, \& Oliva, 
2008; Brady, Konkle, Gill, Oliva, \& Alvarez, 2013; Konkle, Brady, Alvarez, \& Oliva, 2010; Rossion \& Pourtois, 2004).

Similar to the pictures, the words were nouns that described common natural and artificial objects. An object was not represented more than once either in the pictures or words. The word stimuli in all four languages described the same set of objects (see Supplementary Material). 64 (of the 96) pictures and 64 (of the 256) words were organized into unique pictureword pairs from the complete set of stimuli. These 64 picture-word pairs were further divided into two equally sized categories based on the semantic relatedness of the objects depicted by each picture-word pair. In the Related category, the objects described by the picture and the word pair could be easily associated with each other in a specific context in daily life. For example, a picture of a lock paired with the word "key". In the Unrelated category, the objects in each picture-word pair did not share a specific contextual relationship. For example, a picture of a wine-bottle opener paired with the word "lion". The remaining 32 (of 96) pictures and 192 (of 256) words were used as distractor stimuli in our task paradigm (see below). Specifically, each of the 64 picture-word pairs described above was associated with three distractor words. These pair-specific distractor words were always semantically related to the word of the pair and were additionally related to the picture for picture-word pairs in the Related (but not Unrelated) category.

To minimize inter-language semantic differences, we avoided picture-word relationships that might have cultural connotations specific to one language (for example, proverbs specific to French without an equivalent in German/Luxembourgish/English). A native speaker of each language evaluated the corresponding stimulus set for ambiguities.

\section{Paradigm and instructions}

The paradigm consisted of four tasks: (1) Encoding of picture-word pairs, (2) distractor task, (3) Picture recognition, (4) Picture-Word recognition. For clarity, only the English version of the paradigm is described below. All stimuli were displayed using Presentation $®$ Software (Neurobehavioral Systems, Inc) on an LCD screen (size: $68.6 \mathrm{~cm}$ (diagonal), resolution: 1200 pixels $x 800$ pixels, frame rate: $60 \mathrm{~Hz}$ ). The screen was located behind the scanner and was viewed via a mirror installed on the head coil. The required responses across experimental conditions were button-presses with right hand fingers, which were recorded with an MRIcompatible LUMItouch response pad (Photon Control Inc., Burnaby, BC, Canada).

\section{Encoding task}

On each trial of the encoding task, a visual stimulus consisting of a single picture (subtending $3.5^{\circ}$ visual angle (v.a.)) and a single word ( $0.6^{\circ} \mathrm{v}$.a.) below it was centrally displayed on a white screen for $4 \mathrm{~s}$ (see Figure 1A). Participants had to memorize this picture-word pair. 
Additionally, participants judged whether the objects described by the picture and the word were related (i.e., typically associated with each other in daily life) or unrelated. This judgment was reported by pressing one of two pre-designated buttons with the right index or middle finger. Following the stimulus offset, the screen displayed a red cross during the inter-trial interval.

To continuously remind participants of the task requirements and the response mapping, the question "Related?" was displayed at the bottom of the screen (see Figure 1A) along with the response options "Yes" and "No", which were positioned spatially congruent with the response buttons. During the intertrial period, this reminder was also displayed to remind participants that a response could be made even after the stimulus offset.

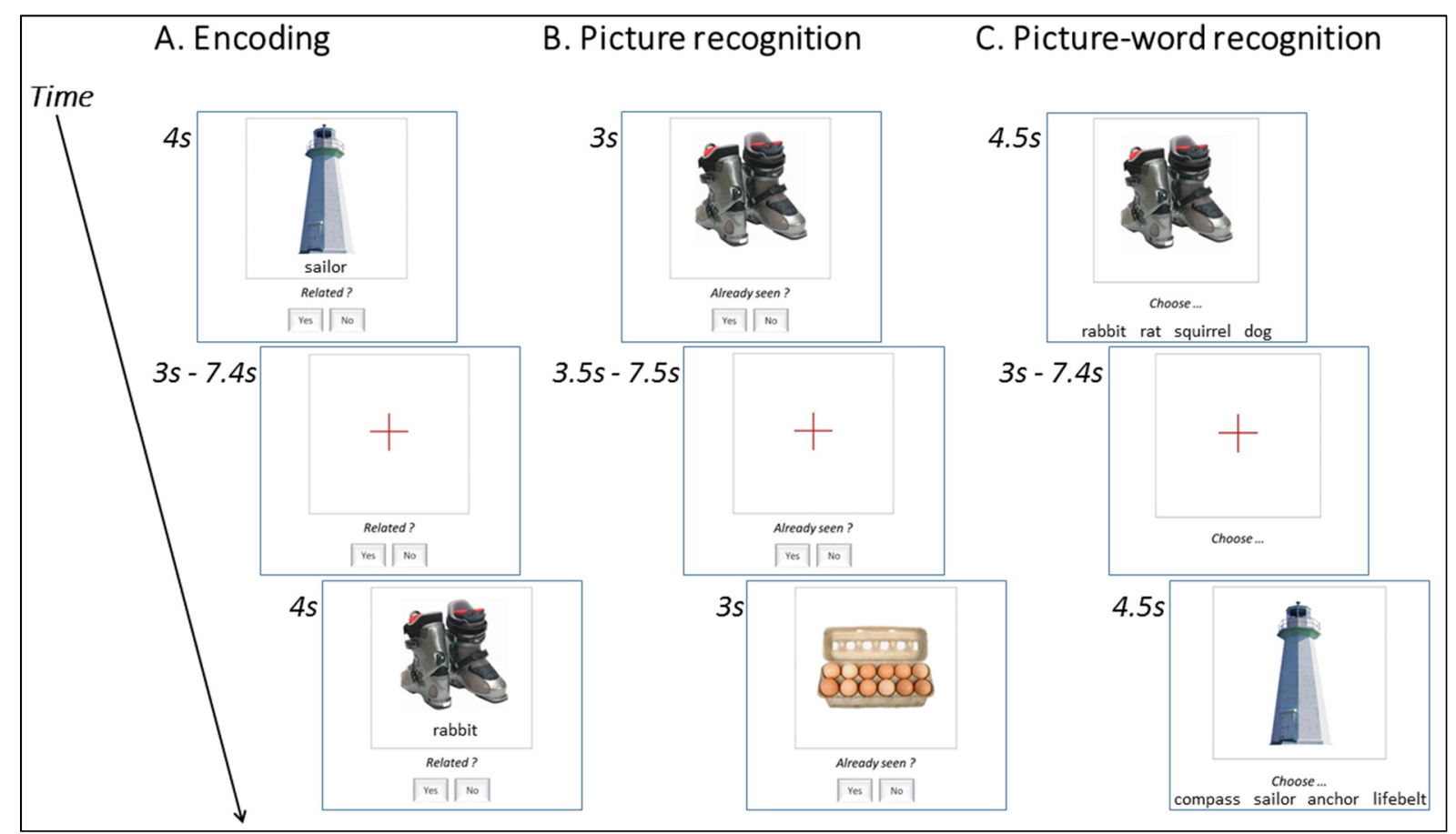

Figure 1. Schematic of task paradigm. Example of timing and stimulus layout (not to scale) on a single trial in the three different task stages. (A) Encoding of picture-word pairs, (B) Picture recognition, (C) Picture-word recognition

The stimuli for the encoding task were the 64 picture-word pairs (described above). A few additional features were incorporated to optimize the trial ordering for event-related fMRI analysis (Liu \& Frank, 2004; Liu, Frank, Wong, \& Buxton, 2001). Firstly, we included 32 null trials (4s duration) so that the overall task effectively had 96 trials belonging to three trial types (i.e., Related, Unrelated, null) with 32 trials each. The null trials were indistinguishable from the inter-trial period, and thus, for the participant, the inter-trial intervals varied over the range 3s-7.4s. Next, the 32 trials of each of the three trial types were presented in a pseudorandom order determined by a Maximum Length Sequence or m-sequence (Aguirre, 2007; Aguirre, 
Mattar, \& Magis-Weinberg, 2011; Buracas \& Boynton, 2002). The m-sequence ensured that all trial types were presented in a counterbalanced manner, i.e., trials of each trial type were equally likely to be preceded by trials of any trial type. The ordering of the stimuli within each trial type was randomized for each participant.

\section{Distractor task}

To ensure that we were testing episodic memory for the stimuli presented during the encoding task, an extended delay of $\sim 24$ minutes followed the encoding task. In this period, structural scans were acquired ( $\sim 11 \mathrm{~min})$, followed by a distractor task ( $6 \mathrm{~min})$ and a resting state scan ( 7min, see Figure 2). The distractor task (adapted from (Kukolja, Goreci, Onur, Riedl, \& Fink, 2016)) was a rapid serial visual presentation task that placed a high demand on sustained attention. This task was used to disrupt working memory processes and explicit verbal rehearsal of the stimuli encountered in the encoding task. In the task, a series of single digits from 0 to 9 were centrally presented in rapid succession (every 600ms) on a black screen, and participants pressed a button with their right index finger whenever the digit " 0 " was displayed. Trials were organized into 5 blocks of 48 stimuli, each separated by a $27 \mathrm{~s}$ inter-block period. Each block contained 3 to 4 zeros.

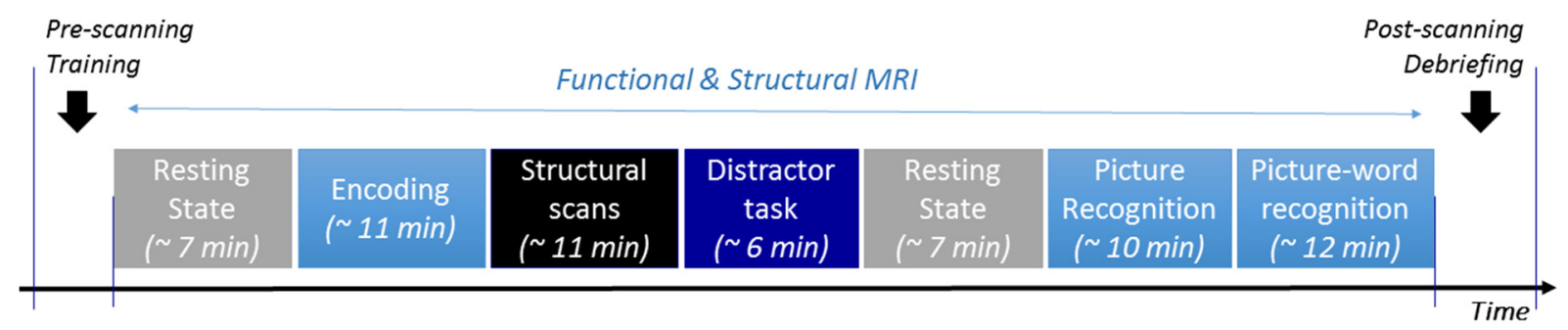

Figure 2. Overall procedure. Description of the different consecutive stages the participants had to follow while inside the MRI scanner.

\section{Picture recognition task}

On each trial of the picture-recognition task, a picture ( $3.5^{\circ} \mathrm{v}$.a.) without any associated word was displayed for a 3s period (Figure 1B). Participants indicated whether or not they had previously seen the picture during the encoding task by pressing one of two pre-designated buttons with either the right index or middle finger. As with the encoding task, a task requirement reminder was continuously displayed at the screen's bottom, i.e., the question "Already seen?" along with the response options "Yes" or "No".

The stimuli for the picture recognition task were the 64 previously seen (i.e., Old) pictures from the encoding task and 32 previously unseen (i.e., New) pictures. No additional null trials were included in this task. The inter-trial interval varied randomly over the range $3.5 \mathrm{~s}-7.5 \mathrm{~s}$. The 
presentation order of the 96 trials belong to the three trial-types (i.e., Related Old, Unrelated Old, New) was determined by an m-sequence, as described above for the encoding task. The ordering of the stimuli within each trial type was randomized for each participant.

\section{Picture-word recognition task}

On each trial of the picture-word recognition task, the stimulus was a picture ( $3.5^{\circ} \mathrm{v} . \mathrm{a}$.) along with a horizontally displayed list of four words ( $0.5^{\circ}$ v.a.) (See Figure $\left.1 \mathrm{C}\right)$. Participants had to identify the word that had been previously seen with the presented picture during encoding. The correct word was always present on each trial. The identified word was indicated by the press of one of four pre-designated buttons with the right index/middle/ring/little finger. Due to a large number of items per stimulus in this task, the trial duration was increased to $4.5 \mathrm{~s}$. As with the encoding and picture-recognition tasks, a task demand reminder ("Choose...") was continuously displayed at the screen's bottom.

The stimuli for this task were the 64 picture-word pairs from the encoding task along with three semantically related distractor words (see Stimulus materials). The relative spatial position of the target word relative to the three distractors was pseudorandomized across trials, based on the Latin Square Design. As in the encoding task, we included 32 null trials (effective inter-trial interval: $3 \mathrm{~s}-7.4 \mathrm{~s}$ ), and an m-sequence determined the trial ordering of the Related/Unrelated/null trial types. The ordering of the stimuli within each trial type was randomized for each participant.

\section{Procedure and Instructions}

Each participant's visual acuity was confirmed using a Snellen chart before the fMRI session. Prior to scanning, participants were provided with detailed written and verbal instructions on how to perform the different tasks. All tasks were practiced at a computer using a different stimulus set from the one used in the actual experiment to familiarize participants with the response demands and the pacing of the stimuli. This practice session was repeated until participants could comfortably perform all tasks. Participants were instructed to respond as accurately and rapidly as possible. Furthermore, we emphasized that there was no response deadline, and a response could be made even after the stimulus disappeared from view. Special care was taken to instruct participants that there was no correct answer for the Related/Unrelated judgments required during the encoding task. Besides, we emphasized that the relatedness of the objects in the picture-word pair depended on whether this relationship was "typical" and not whether they could imagine a hypothetical relationship between the objects. Throughout this instruction period, avoiding unnecessary head and body movements in the scanner was emphasized. Following the scanning, participants were debriefed to assess their compliance with task instructions and fatigue levels. 


\section{Behavioral analysis}

\section{Individualization of Related/Unrelated categories}

Even though the picture-word pairs were designed to belong to either of two semantic categories (i.e., Related or Unrelated), participants could differ in their semantic knowledge and experience with the objects described by the stimuli. To accommodate this possibility, for our analyses, the picture-word pairs in the encoding task were re-categorized based on each participant's subjective judgments about picture-word relatedness. All analyses assessing the behavior and brain activity evoked by the Related/Unrelated stimulus categories were based on this individual-specific re-categorization of the stimuli.

Since the pre-designed categories were used to optimize the trial ordering for $f M R I$ analysis (see paradigm above), the degree of agreement between our pre-designed stimulus categorization and the individual-specific categorization was an important concern. Therefore, the degree of agreement was quantified as the proportion of trials where a participant's judgment of picture-word relatedness (during encoding) corresponded to the pre-designed categorization of relatedness.

\section{Accuracy and Response Times}

Due to the relatively low false alarm rates (i.e., incorrect New judgments) in the picturerecognition task, we used the balanced accuracy (Brodersen, 2010) to measure overall performance rather than the classical $d$-prime measure. The balanced accuracy was equal to $(\mathrm{H}+\mathrm{CR}) / 2$ where $\mathrm{H}$ is the hit rate (i.e., the proportion of correctly recognized Old pictures) and $\mathrm{CR}$ is the correct rejection rate (i.e., the proportion of new pictures that were correctly judged as being New). For all accuracy calculations, the failure to respond to a stimulus was treated as an error.

The Response Time (RT, i.e., the elapsed time from stimulus onset to the response) was only estimated for correct responses in all experimental conditions. To obtain a robust estimate of the characteristic RT for each individual in each condition, we calculated the mean RT after trimming the highest and lowest RT values (10\% at each end) (Ratcliff, 1993; Wilcox \& Keselman, 2003; Zandt, 2002).

\section{Inter-language differences}

Participants were divided into separate groups depending on the language selected for the stimuli. To statistically assess inter-group differences, a general linear model (GLM) was used to evaluate the extent to which the behavior (i.e., accuracy and RT) in each of the experimental conditions (encoding, picture-recognition, and picture-word recognition) could be independently explained by the stimulus properties (i.e., Related/Unrelated, Old/New) and by 
the stimulus language. Since an accuracy measure was undefined for the encoding task, the degree of agreement was instead used as a proxy measure for accuracy. To correct for the relative differences in the sizes of the language groups, a Leave-One-Out (LOO) procedure (Bishop, 2006) was carried out for each GLM comparison. This procedure allowed a resampling of the sample to ensure that the obtained results were not fortuitous and sensitive to outlier values.

Other epidemiological factors could potentially drive inter-group differences (if present). Although a large amount of epidemiological data were collected per participant, we only considered parameters of immediate relevance to the experiment itself, namely, age, gender, number of years of education, MMSE score, and the number of practiced languages (selfreported). In-depth analysis on the amount of practiced multilingualism in daily life is not part of the present study.

\section{Statistical analyses}

All statistical analyses on epidemiological and behavioral data were performed with SAS System V9.4 (SAS Institute, Cary, NC, US). Means are reported with standard deviations. For all statistical tests, normality was evaluated using the Kolmogorov-Smirnow test (when $n>50$ ) and the Shapiro Wilk test (when $n<50$ ). For normal distributions, we used a t-test (paired or unpaired, $t$ ). For non-normal distribution, non-parametric tests were used: (a) The Wilcoxon signed-rank test ( $Z$ ) for within-subject comparisons; (b) the Wilcoxon Mann Whitney test $\left(U\right.$ ) for two-sample comparisons. Finally, a Chi-square test $\left(X^{2}\right)$ was used to compare gender between participants having chosen French and those having chosen German to measure the independence of both variables in a 2-by-2 table. Behavioral results were reported in the format: Test (degrees of freedom) $=$ Statistic, $p=$ value .

\section{fMRI Data}

Image acquisition and preprocessing

Functional and structural MR images were acquired on a 3T MR scanner (Siemens Tim Trio, Erlangen, Germany) with a 12-channel phased-array head coil. Functional images were measured using a $\mathrm{T}^{*}$-weighted gradient-echo planar imaging (EPI) sequence (repetition time (TR): $2200 \mathrm{~ms}$, echo time (TE): $30 \mathrm{~ms}$, flip angle (FA): $90^{\circ}$, field of view (FoV): $200 \mathrm{~mm} \mathrm{x}$ $200 \mathrm{~mm}$ ). Each volume had 36 slices (interleaved series, thickness: $3.1 \mathrm{~mm}$, inter-slice gap: $0.49 \mathrm{~mm}$ ) with an in-plane resolution of $3.1 \mathrm{~mm} \times 3.1 \mathrm{~mm}$ (matrix size: $64 \times 64$ ). The structural scan used a T1-weighted magnetization-prepared rapid gradient echo (MPRAGE) sequence (TR: $2250 \mathrm{~ms}$, TE: $3.03 \mathrm{~ms}$, FA: $9^{\circ}$, TI: $900 \mathrm{~ms}$, FOV: $256 \mathrm{~mm} \times 245 \mathrm{~mm}$ ) to obtain a highresolution image (176 slices, matrix size: $256 \times 256$, inter-slice gap: $0.5 \mathrm{~mm}$, voxel size: $1.0 \mathrm{~mm}$ $\times 1.0 \mathrm{~mm} \times 1.0 \mathrm{~mm})$. An additional structural image was acquired using a T2-weighted fluid- 
attenuated inversion recovery (FLAIR) sequence, but this image was not used for preprocessing/analysis. Each task was performed on a separate scanning run. Each functional scan began with a 6TR task-free period to ensure that the MR signal reached a steady state. Since the BOLD signal evolves over multiple seconds, each functional run also ended with a 6TR task-free period to measure brain activity evoked by the final stimuli.

Image preprocessing and statistical analysis were performed with the SPM12 software (Wellcome Centre for Human Neuroimaging, London, UK) implemented for a MATLAB programming environment (MathWorks Inc., Natick, Massachusetts, USA). For preprocessing and statistical analyses, the acquired images were converted from the Siemens DICOM format to the NIFTI format using the dcm2nii utility (Li, Morgan, Ashburner, Smith, \& Rorden, 2016). Functional images (EPIs) were spatially realigned (to the first volume) and unwarped using the iterative realign/unwarp algorithm implemented in SPM12 to correct for head motion and associated magnetization artefacts (Andersson, Hutton, Ashburner, Turner, \& Friston, 2001). The EPIs were then slice-time corrected (relative to the middle slice). The mean EPI was coregistered to the structural image. Using SPM12's unified segmentation/normalization algorithm, the structural image was segmented to distinguish white and gray matter and then deformed to match a standard Montreal Neurological Institute (MNI) template brain image. The deformation fields estimated from this segmentation/normalization procedure were applied to all EPIs to transform them into standard MNI space (normalization) followed by resampling to a voxel size of $3 \mathrm{~mm} \times 3 \mathrm{~mm} \times 3 \mathrm{~mm}$ ( $4^{\text {th }}$ degree B-spline interpolation). The normalized EPIs were smoothed with an isotropic 8mm full-width-at-half-maximum (FWHM) Gaussian kernel.

Following preprocessing, fMRI datasets from 2 (out of 62) participants were excluded from further analyses as they were incomplete due to technical difficulties encountered during scanning. However, these technical problems did not affect the behavioral data acquired from these two participants.

\section{Statistical analysis}

Statistical analyses were conducted within a conventional mass-univariate framework where the evoked hemodynamic response at each voxel was independently modeled using a general linear model (GLM). Each experimental condition (i.e., encoding, picture recognition, and picture-word recognition) was modeled as a separate session. Functional data from the distractor task were not analyzed as this task was included to disrupt working memory processes and explicit verbal rehearsal of the stimuli encountered in the encoding task (see above). For all conditions, the estimated first-level models shared the following properties. At every voxel, the neural response evoked by each trial was modeled as a boxcar with zero duration convolved with the canonical hemodynamic response function (HRF). The regressors of interest only modeled correct trials. Additional regressors of non-interest were included to 
account for incorrect trials. The 6 head-movement parameters estimated during spatial realignment (i.e., translation and rotation relative to the $\mathrm{X}, \mathrm{Y}, \mathrm{Z}$ axes) and the framewise displacement (i.e., the relative displacement of each volume relative to the previous volume) (Power, Barnes, Snyder, Schlaggar, \& Petersen, 2012) were included as covariates to account for head-movement effects. The BOLD time series at each voxel was high pass filtered (1/128 $\mathrm{Hz}$ ) to remove slow trends.

We defined regressors corresponding to the Related and Unrelated trials to assess semantic effects in the different tasks. For the picture-recognition task, the GLM included an additional regressor for the New trials. Contrasts were performed at the individual level (i.e., first level), and these contrast images (without any additional smoothing) were used for group (i.e., second-level) statistics.

All second-level statistics reported here were corrected for multiple comparisons at the threshold of $\mathrm{p}<0.05$ (cluster-level Family Wise Error (FWE)) with a cluster-forming threshold determined at $p<0.001$ (uncorrected). We also report the minimum cluster size (in voxels) to meet this threshold for each of the contrasts as estimated in SPM12 (T. E. Nichols et al., 2016). When cluster-level correction produced overly large clusters, we use a stricter threshold of $p$ $<0.05$, voxel-wise Family Wise Error correction. For exploratory purposes, the conjunction between activity maps was assessed by the overlap in voxels that are part of statistically significant clusters in each map, i.e., the minimum-T criterion (T. Nichols, Brett, Andersson, Wager, \& Poline, 2005).

Brain regions obtained from these analyses were identified using the SPM Anatomy Toolbox (Eickhoff et al., 2005), and surface visualization is shown using the Surf Ice software (https://www.nitrc.org/projects/surfice). 


\section{Results}

\section{Semantic effects during picture-word encoding}

We used the data from all participants (irrespective of stimulus language) to evaluate the main effect of semantic relatedness judgments on memory performance.

Participants' subjective categorization of picture-word pairs as either Related or Unrelated showed a high degree of agreement to the pre-designed stimulus categories (94.5 $\pm 3.7 \%$ ). This high degree of the agreement confirmed that participants had correctly interpreted our task instructions. Importantly, it also confirmed that the relatedness judgments, although subjective, were not arbitrary but highly consistent between participants and our predesigned stimulus categories.

The mean response time (RT) for Related judgments (1749 $\pm 452 \mathrm{~ms}$ ) was shorter than for Unrelated judgments (1877 $\pm 431 \mathrm{~ms}, Z[61]=657.5, p<0.0001)$ (Figure 3A). The contrast Related > Unrelated revealed higher activation, especially over the left hemisphere (Figure 3B, Table 1), including the left middle temporal gyrus (MTG), left posterior cingulate cortex (PCC), left anterior cingulate cortex (ACC), left inferior frontal gyrus (IFG), and bilaterally over the angular gyrus. Inversely, the contrast Unrelated > Related did not reveal any statistically significant activity difference across the brain.

Table 1. Related vs. Unrelated during encoding: Peak coordinates of significant clusters

\begin{tabular}{|c|c|c|c|c|c|c|c|c|}
\hline \multirow[t]{2}{*}{ Contrast } & \multirow[t]{2}{*}{ Anatomical Region } & \multirow[t]{2}{*}{ Hem. } & \multicolumn{3}{|c|}{ Coordinates } & \multirow{2}{*}{$\begin{array}{c}t- \\
\text { value }\end{array}$} & \multirow{2}{*}{$\begin{array}{c}p- \\
\text { value }\end{array}$} & \multirow{2}{*}{$\begin{array}{c}\text { Cluster } \\
\text { size }\end{array}$} \\
\hline & & & $\mathbf{x}$ & y & $\mathbf{z}$ & & & \\
\hline \multirow[t]{6}{*}{ Rel > Unrel } & Angular Gyrus & $\mathrm{L}$ & -48 & -67 & 35 & 8.60 & 0.000 & 516 \\
\hline & MTG & L & -60 & -46 & -7 & 8.12 & 0.000 & 281 \\
\hline & PCC & $\mathrm{L}$ & -3 & -52 & 26 & 7.81 & 0.000 & 464 \\
\hline & ACC & L & -6 & 47 & 17 & 6.56 & 0.000 & 1460 \\
\hline & Angular Gyrus & $\mathrm{R}$ & 48 & -64 & 41 & 6.00 & 0.000 & 241 \\
\hline & IFG (p. Orbitalis) & $\mathrm{L}$ & -42 & 47 & -10 & 5.35 & 0.031 & 80 \\
\hline Unrel > Rel & & & rvi & aft & rres & & & \\
\hline
\end{tabular}

Clusters identified at threshold of $p<0.05$, FWE-cluster-corrected, cluster-forming threshold $=80$ voxels $(p<0.001$, uncorr.). Peak locations are in MNI coordinates. Hemisphere (Hem.) reported as L/R (Left/Right). ACC: anterior cingulate cortex, PCC: posterior cingulate cortex, IFG: inferior frontal gyrus, MTG: Middle Temporal Gyrus 


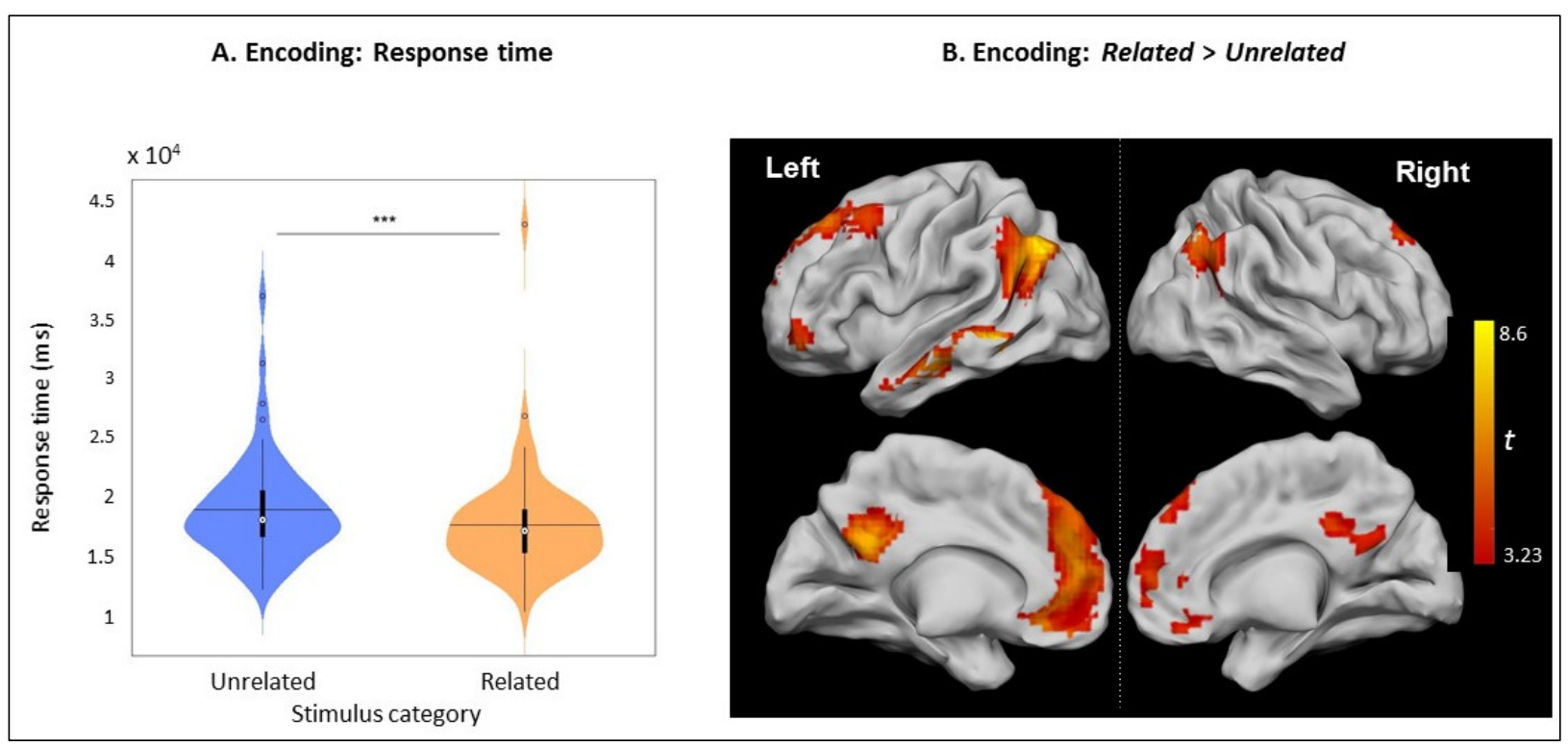

\section{Figure 3. Related vs. Unrelated during encoding}

A. Violin plots of RTs for Related and Unrelated judgments during encoding (*** $p<0.001$ ), horizontal lines represent the median, vertical black bars are a box plot, a center white circle represents the means.

B. Clusters with increased activity during Related versus Unrelated judgments $(p<0.05$, FWE-cluster corrected, cluster-forming threshold $=80$ voxels (at $\mathrm{p}<0.001$ (uncorr.)).

\section{Semantic effects on picture-recognition}

Accuracy for differentiating Old and New pictures was high $(89.8 \pm 7.5 \%)$ and was significantly greater than random chance $(50 \%, U[61]=5797, p<0.0001)$. Importantly, the mean accuracy in recognizing Old pictures that were part of Related picture-word pairs during encoding $(92.5 \pm 7.7 \%)$ was greater than for Old Unrelated pictures $(82.9 \pm 12.8 \%, t[61]=$ 7.24, $p<0.0001$, Figure 4A). Furthermore, the mean RT to recognize Old Related pictures $(1082 \pm 158 \mathrm{~ms})$ was shorter than for Old Unrelated pictures $(1247 \pm 236 \mathrm{~ms}, Z[61]=905.5$, $p<0.0001$, Figure 4B).

The accuracy in recognizing New pictures $(92.7 \pm 9.6 \%)$ was greater than for Old Unrelated pictures $(t[61]=4.72, p<0.0001)$ but was not significantly different from the accuracy for Old Related pictures $(Z[61]=-109.5, p \geq 0.3505)$. However, the mean RT to recognize Old Related pictures was shorter than for New judgments (1253.5 $\pm 210.8 \mathrm{~ms}$, $t[61]=6.17, p<0.0001$ ), while the RTs for New judgments and Old Unrelated pictures were not significantly different $(t[61]=0.20, p=0.8450)$. 


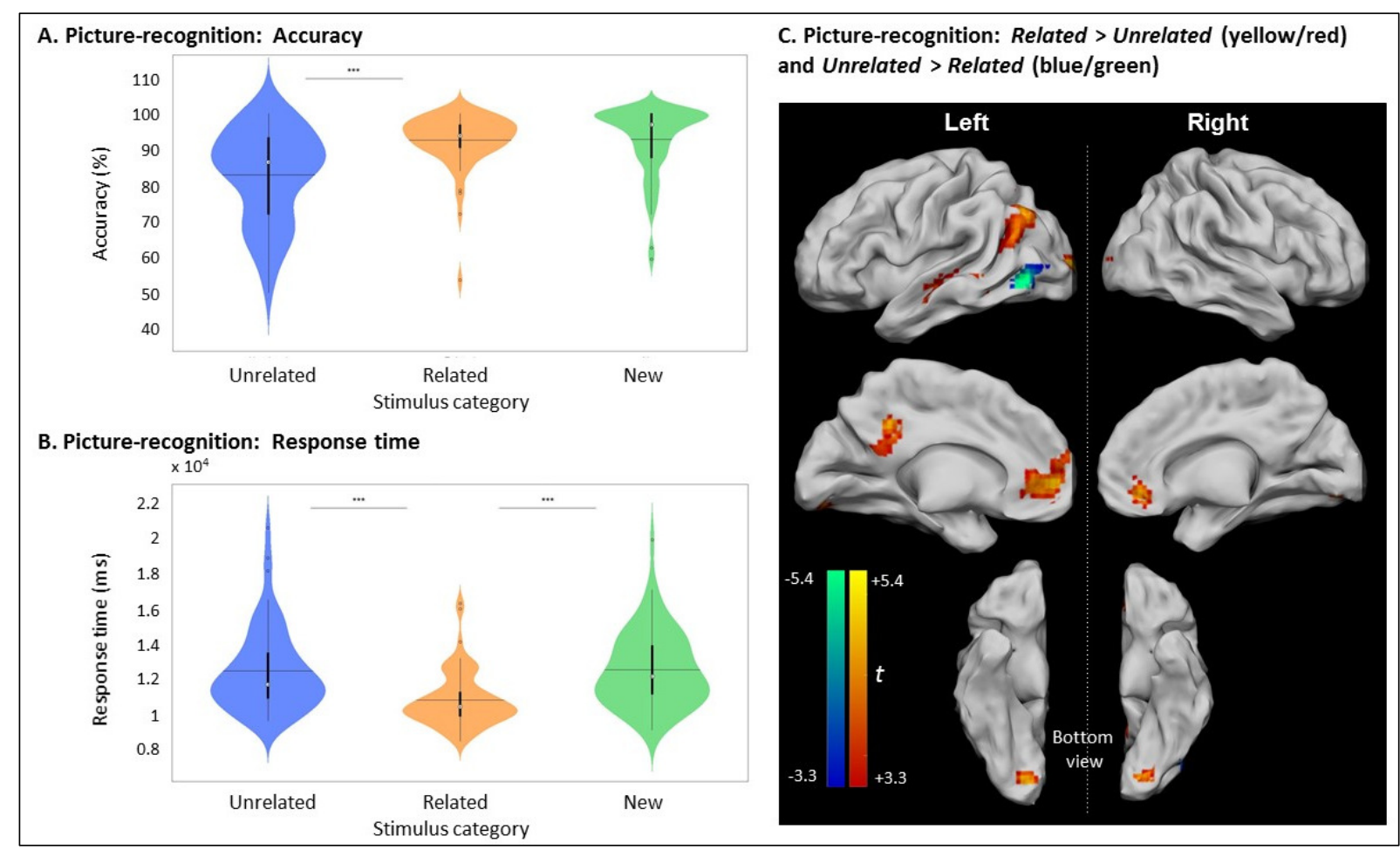

\section{Figure 4. Picture recognition based on relatedness during encoding}

A. Recognition accuracy for New stimuli and Old stimuli, depending on their relatedness during encoding, i.e., Unrelated or Related). B. Response Times for correct New and correct Old judgments depending on their relatedness during encoding. ${ }^{* * *}: p<0.001$ ) Violin plots (horizontal lines represent the median, vertical black bars are a box plot, center white circles represent the means). C. Clusters with significant activity during recognition for Related > Unrelated (red scale) and for Unrelated $>$ Related (blue scale), p < 0.05, FWE-cluster corrected, clusterforming threshold $=84$ voxels (at $p<0.001$, uncorr).

Brain activity elicited by recognizing Old Unrelated pictures was higher than for the Old Related pictures only in the left inferior occipital gyrus (Figure 4C, Table 2). However, consistent with the activity differences at encoding, the recognition of Old Related pictures evoked more significant activity than for Old Unrelated pictures over several regions, including the left MTG, the left PCC, the left ACC, the left middle occipital gyrus, and the right lingual gyrus (Figure 4C, Table 2). 
Table 2. Picture recognition: Peak coordinates of significant clusters for all contrasts

\begin{tabular}{|c|c|c|c|c|c|c|c|c|}
\hline \multirow[t]{2}{*}{ Contrast } & \multirow[t]{2}{*}{ Anatomical region } & \multirow[t]{2}{*}{$\mathbf{H}$} & & ordine & & \multirow[t]{2}{*}{$\begin{array}{c}t- \\
\text { value }\end{array}$} & \multirow[t]{2}{*}{$\begin{array}{c}p- \\
\text { value }\end{array}$} & \multirow[t]{2}{*}{$\begin{array}{c}\text { Cluster } \\
\text { size } \\
\text { (voxels) }\end{array}$} \\
\hline & & & $\mathbf{x}$ & $\mathbf{y}$ & $\mathbf{z}$ & & & \\
\hline \multirow[t]{6}{*}{ Rel > Unrel } & ACC & $\mathrm{L}$ & -6 & 50 & -1 & 5.32 & 0.000 & 343 \\
\hline & Middle Occipital Gyrus & L & -15 & -100 & 5 & 5.29 & 0.003 & 146 \\
\hline & Middle Occipital Gyrus & L & -39 & -70 & 35 & 4.96 & 0.000 & 244 \\
\hline & MTG & L & -51 & -43 & -4 & 4.90 & 0.018 & 95 \\
\hline & PCC & L & -3 & -46 & 29 & 4.86 & 0.004 & 134 \\
\hline & Lingual Gyrus & $\mathrm{R}$ & 18 & -85 & -10 & 4.79 & 0.002 & 157 \\
\hline Unrel > Rel & Inferior Occipital Gyrus & $\mathrm{L}$ & -45 & -70 & -4 & 5.78 & 0.028 & 84 \\
\hline \multirow[t]{6}{*}{ Old $>$ New } & Inferior Parietal Lobule & $\mathrm{L}$ & -39 & -55 & 44 & 12.59 & 0.000 & 1388 \\
\hline & Middle Frontal Gyrus & L & -42 & 8 & 53 & 10.69 & 0.000 & 754 \\
\hline & MTG & L & -60 & -40 & -4 & 7.90 & 0.000 & 41 \\
\hline & MTG & L & -63 & -25 & -7 & 5.04 & 0.028 & 1 \\
\hline & Angular Gyrus & $\mathrm{R}$ & 36 & -64 & 41 & 6.76 & 0.000 & 141 \\
\hline & Posterior-Medial Frontal & L & -6 & 20 & 50 & 6.17 & 0.000 & 41 \\
\hline \multirow[t]{3}{*}{ New $>$ Old } & Postcentral Gyrus & $L$ & -45 & -25 & 62 & 6.22 & 0.005 & 148 \\
\hline & Postcentral Gyrus & $\mathrm{L}$ & -63 & -22 & 23 & 5.52 & 0.009 & 129 \\
\hline & Inferior Temporal Gyrus & $\mathrm{R}$ & 51 & -61 & -4 & 4.62 & 0.029 & 96 \\
\hline
\end{tabular}

Clusters for Rel vs Unrel were identified at threshold of $p<0.05$, FWE-cluster-corrected cluster-forming threshold $=84$ voxels (at $p<0.001$, uncorr). For the Old vs New contrasts, contrasts are reported at a stricter threshold of $\mathrm{p}<0.05$, voxel-wise FWE due to the large clusters obtained at cluster-corrected thresholds. Peak coordinates are reported in $\mathrm{MNI}$ coordinates. Hemisphere $(\mathrm{H})$ reported as L/R (Left/Right). ACC: anterior cingulate cortex, MTG: Middle Temporal Gyrus, PCC: posterior cingulate cortex.

New judgments elicited more significant activity than Old judgments (irrespective of whether the pictures were Related or Unrelated at encoding) in two clusters in the left postcentral gyrus and the right inferior temporal gyrus (Figure 5A, Table 2). Old judgments elicited more significant activity than New judgments in the left inferior parietal lobule, the left posterior medial frontal cortex, the left middle frontal gyrus, the left MTG, and the right angular gyrus.

A subset of clusters presenting a recognition effect (i.e., Old $>$ New) showed an overlap with the relatedness effect (i.e., Old Related > Old Unrelated), namely, in the left angular gyrus and PCC (Figure 5B). Notably, activity differences in the ACC, which were found at encoding due to relatedness, were not observed during recognition (i.e., in the Old > New contrast). 


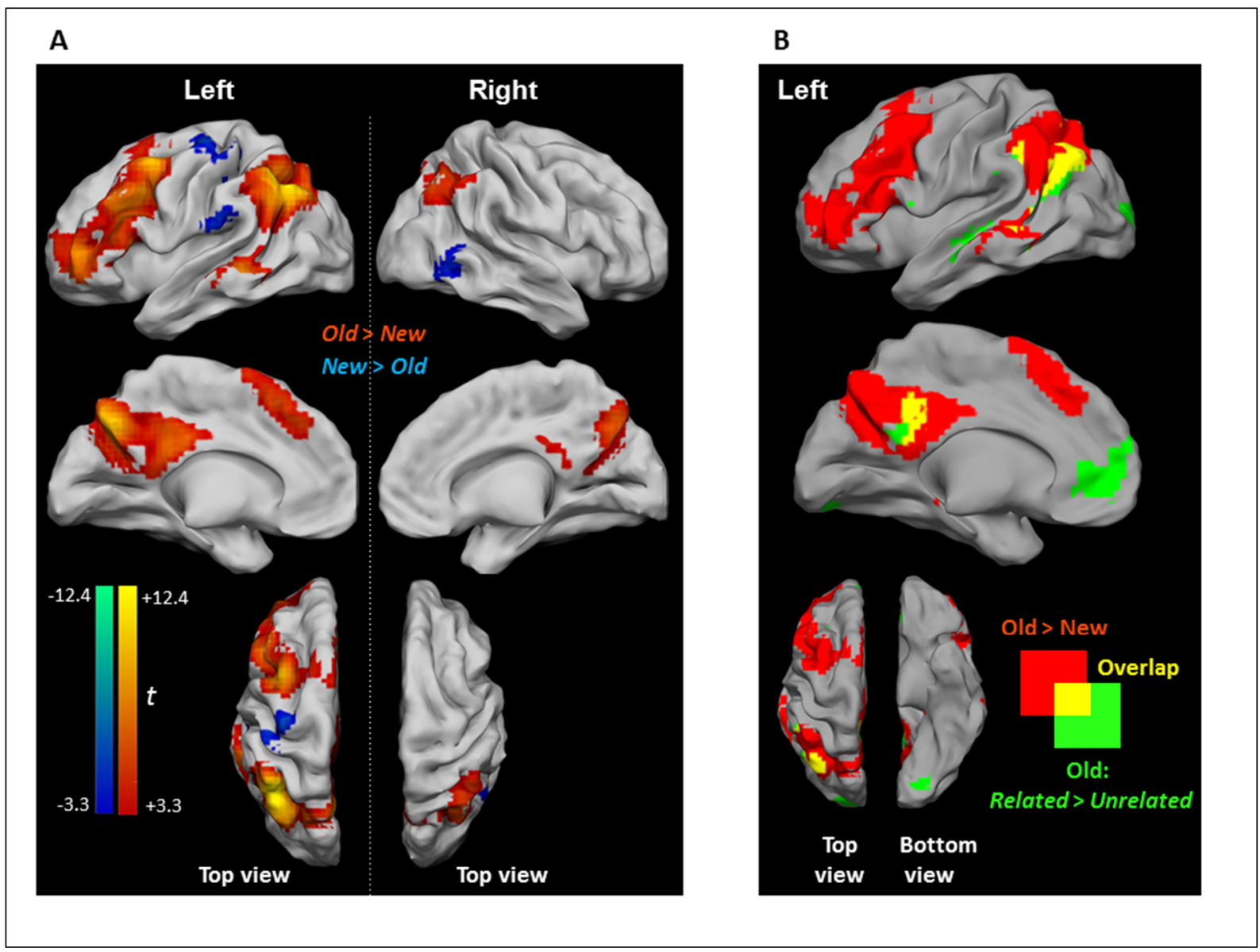

\section{Figure 5. Activity differences during picture-recognition}

A. Clusters showing significant activity for Old > New (red scale) and for New > Old (blue scale). Due to the large cluster size obtained at cluster-corrected thresholds, contrasts are reported at a stricter threshold of $p<0.05$, voxe/wise FWE. B. Overlap between Old > New (red) and Related > Unrelated (green) (Figure 4C) with the shared area shown in yellow.

\section{Semantic effects on picture-word recognition}

The mean accuracy in correctly identifying an Old word was $64.3 \pm 15.7 \%$, which was significantly greater than random chance $(25 \%, U[61]=5673, p<0.0001)$. The mean accuracy to identify words that were part of Related picture-word pairs (78.8 $\pm 15.4 \%)$ was significantly higher than for Unrelated words $(54.4 \pm 15.7 \%, t[61]=-12.25, p<0.0001$, Figure $6 \mathrm{~A})$. This effect of relatedness during encoding was also evident in the considerably shorter RT to identify words that were part of Related picture-word pairs at encoding ( $2458 \pm 562 \mathrm{~ms}$ ), in comparison with words from Unrelated pairs $(3323 \pm 640 \mathrm{~ms}, t[60]=17.85, p<0.0001$, Figure 6B). 


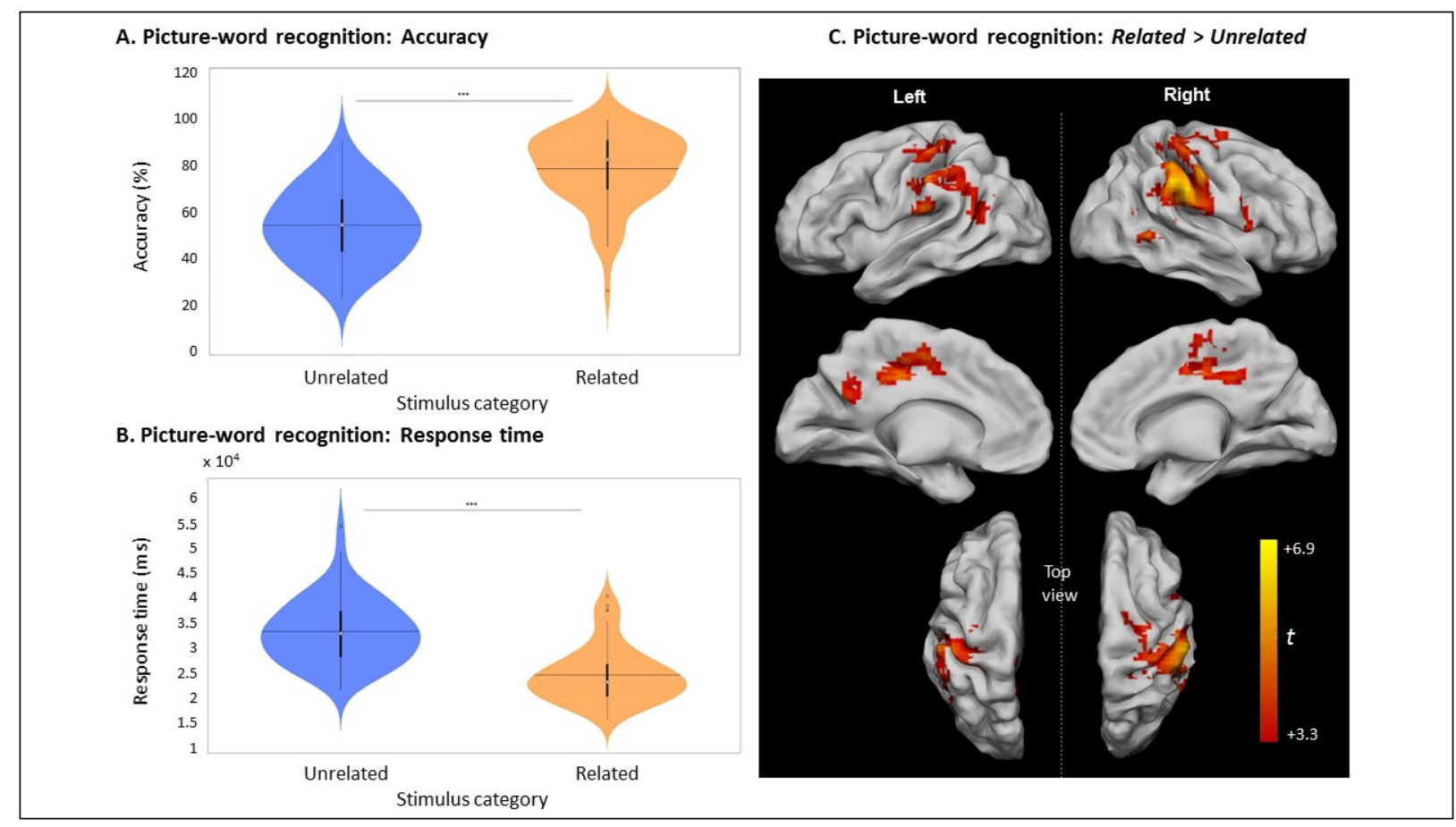

Figure 6. Picture-word recognition according to the judgment about the relatedness of

\section{pairs at encoding}

A. Recognition accuracy for picture-word pairs depending on their relatedness during encoding, i.e., Unrelated or Related). B. Response Times for picture-word pairs depending on their relatedness during encoding. $(* \star *: p<0.001)$ Violin plots (horizontal lines represent the median, vertical black bars are a box plot, center white circles represent the mean). C. Clusters with significant activity during picture-word recognition for Related > Unrelated, $\mathrm{p}<0.05$ FWE-cluster corrected, cluster-forming threshold $=84$ voxels (at $p<0.001$, uncorr.).

Similar to the encoding and picture recognition, the neural activity of the last session of picture-word recognition for Related pairs was greater than for Unrelated pairs (Figure 6C, Table 3). Activity differences were present in the left inferior parietal lobule, the right supramarginal gyrus, the left middle cingulate cortex (MCC), the right putamen, and the right cerebellum. There was no significant activity difference for the contrast Old Unrelated > Old Related. 
bioRxiv preprint doi: https://doi.org/10.1101/2021.09.07.459272; this version posted September $8,2021$. The copyright holder for this preprint (which was not certified by peer review) is the author/funder, who has granted bioRxiv a license to display the preprint in perpetuity. It is made available under aCC-BY-NC 4.0 International license.

Table 3. Picture-word recognition: Peak coordinates for Related vs. Unrelated

\begin{tabular}{|c|c|c|c|c|c|c|c|c|c|}
\hline Contrast & Anatomical region & $\mathbf{H}$ & \multicolumn{2}{|c|}{ Coordinates } & $\begin{array}{c}\boldsymbol{t} \text { - } \\
\text { value }\end{array}$ & $\begin{array}{c}\boldsymbol{p} \text { - } \\
\text { value }\end{array}$ & $\begin{array}{c}\text { Cluster } \\
\text { size }\end{array}$ \\
\hline Rel > Unrel & Inferior Parietal Lobule & $\mathrm{L}$ & -57 & -25 & 44 & 6.90 & 0.000 & 717 \\
\hline & Supramarginal Gyrus & $\mathrm{R}$ & 60 & -37 & 38 & 6.47 & 0.000 & 1065 \\
\hline & MCC & $\mathrm{L}$ & -3 & -22 & 41 & 5.58 & 0.000 & 584 \\
\hline & Putamen & $\mathrm{R}$ & 33 & 2 & 8 & 4.70 & 0.004 & 158 \\
\hline & $\begin{array}{c}\text { Cerebellum } \\
\text { (IV-V) }\end{array}$ & $\mathrm{R}$ & 21 & -43 & -19 & 4.17 & 0.033 & 94 \\
\hline & & & & & & & & \\
\hline
\end{tabular}

Unrel > Rel

Nothing survived after correction

Clusters identified at threshold of $p<0.05$, FWE-cluster-corrected. Cluster-forming threshold $=94$ voxels (at $p<0.001$ uncorr.) Peak coordinates are reported in MNI coordinates. Hemisphere $(H)$ reported as L/R (Left/Right). MCC: middle cingulate cortex

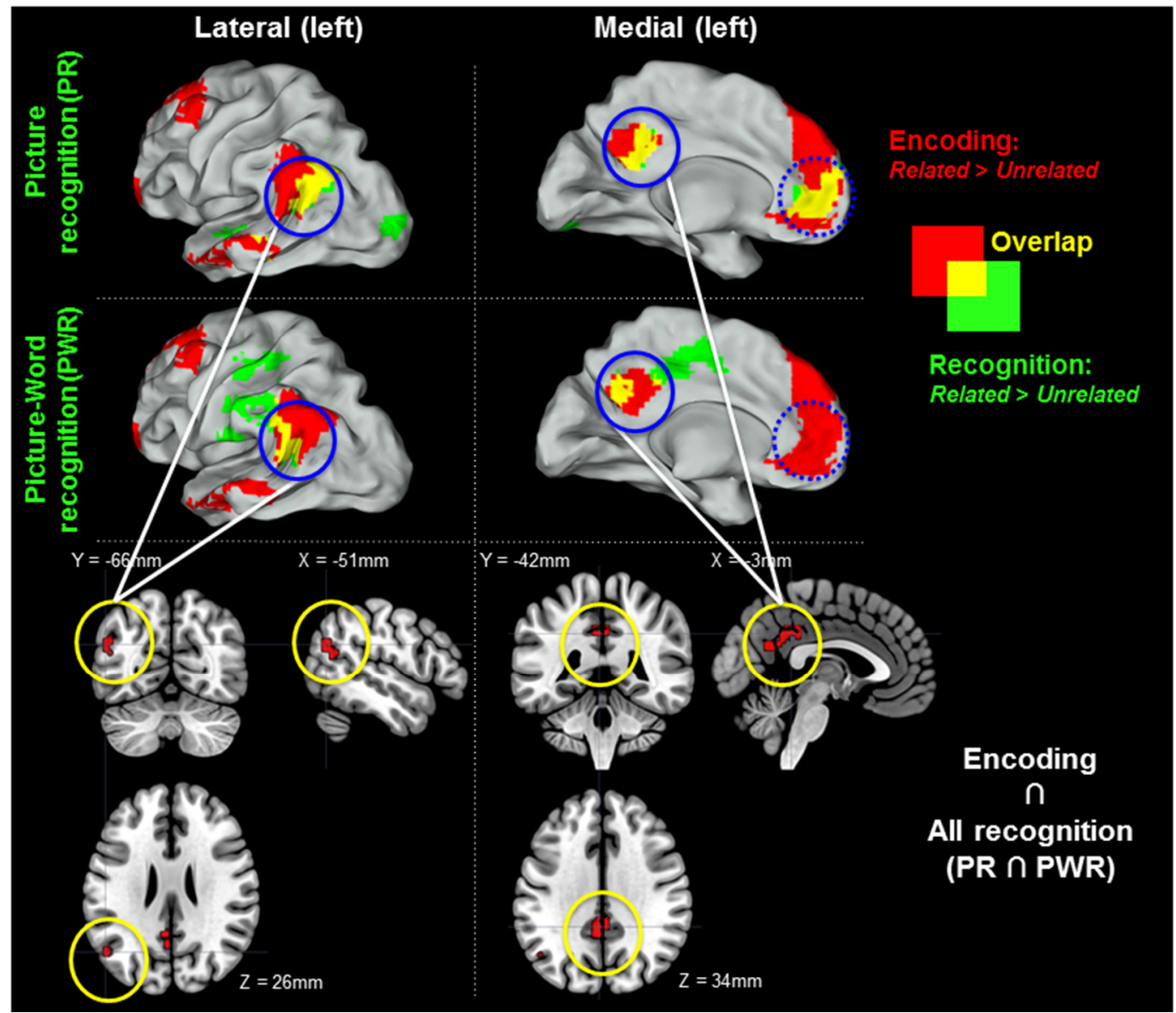

\section{Figure 7. Related > Unrelated during encoding and recognition}

Regions with increased activity for Related > Unrelated at encoding are shown in red in the upper two rows. Recognition-related activity increases for (Old) Related > (Old) Unrelated are shown in green: (i) for picture recognition $(\mathrm{PR})$ in the first row and (ii) for picture-word recognition (PWR) in the middle row. The overlap between encoding and recognition-related activity is indicated in yellow. Solid blue circles indicate regions of activity overlaps between encoding and all recognition (encoding $\cap$ PR $\cap$ PWR). The shared overlaps are shown in sectional views in the bottom row. Dotted blue circles indicate overlaps between encoding and either PR or PWR but not both. There was no overlap in the right hemisphere. The figure shows clusters whose peak survived a size-threshold for $p<0.05$ FWE-corrected (cluster-forming threshold at $p<0.001$ uncorr.). 
Figure 7 shows the overlap of regions exhibiting semantically modulated activity during encoding, picture recognition, and picture-word recognition. The semantic modulations during encoding and picture recognition showed an overlap at multiple regions including the left angular gyrus, PCC, and the ACC. However, both encoding and picture recognition showed a limited overlap with picture-word recognition in the angular gyrus shared across all tasks (encoding $\cap$ picture-recognition $\cap$ picture-word recognition).

\section{Stimulus language did not modulate semantic effects}

Forty-two participants (67.7\%) chose German as their preferred stimulus language (i.e., the most comfortable language to read and answer rapidly) while $18(29.0 \%)$ chose French and 2 (3.3\%) participants chose English. None of the participants chose Luxembourgish as the stimulus language. Due to the low number of participants selecting English, we restricted our analysis of language-modulated task effects to the subgroups using German (GER) and French (FR), respectively.

The GER and FR subgroups were similar in gender ratio, age, education, language ability, and cognitive status (MMSE scores). The mean values for these different factors are listed in Table 4. There were no statistically significant between-group differences in these data.

Table 4. Population features

\begin{tabular}{|c|c|c|c|}
\hline & $\begin{array}{l}\text { Subgroup } \\
\text { using } \\
\text { German } \\
\text { (GER) }\end{array}$ & $\begin{array}{l}\text { Subgroup } \\
\text { using } \\
\text { French } \\
\text { (FR) }\end{array}$ & Statistical tests ${ }^{\phi}$ \\
\hline Gender ratio (f/m) & 1.47 & 1.25 & $X^{2}(1)=0.0816, p=0.7751$ \\
\hline Age (y) & $69 \pm 5$ & $71 \pm 6$ & $U(59)=617.5, p=0.2704$ \\
\hline Education (y) & $14.7 \pm 4.0$ & $16.1 \pm 5.0$ & $U(59)=590.5, p=0.5064$ \\
\hline MMSE (score) & $28.86 \pm 1.26$ & $28.83 \pm 1.25$ & $U(59)=545.0, p=0.9525$ \\
\hline \multicolumn{4}{|l|}{ Languages } \\
\hline In total ${ }^{\star}(\mathrm{n})$ & $5.3 \pm 1.3$ & $5.5 \pm 1.4$ & $U(59)=527.5, p=0.6539$ \\
\hline Current" ${ }^{\#}(\mathrm{n})$ & $4.1 \pm 1.1$ & $4.5 \pm 1.6$ & $U(59)=491.5, p=0.4027$ \\
\hline \multicolumn{4}{|c|}{$\begin{array}{l}*: \text { corresponds to the total number of languages practiced lifelong } \\
\#: \text { corresponds to the number of languages practiced at the time of the study } \\
\phi: \text { The sample size is reduced by two because the subgroup using English was excluded. In each group, } \\
\text { means and standard deviations were reported for continuous variables. } \\
\text { MMSE: Mini-Mental State Examination }\end{array}$} \\
\hline
\end{tabular}

Besides, the two groups showed similar degree of agreement to the pre-designed stimulus categories (mean agreement difference $=0.644 \% \pm 1.036(U(59)=510.0$, $p=0.5236$ ). Using a GLM, we evaluated whether the semantic effects on accuracy and RT in each tasks (encoding, picture recognition, and picture-word recognition) were modulated by the stimulus language. As shown in Table 5 and Figure 8, the semantic effects observed at the group level were also present within each subgroup. However, there were no statistically 
significant interaction effects for any of the behavioral measures considered. Since the GER and FR subgroups had different sizes (42 and 18, respectively), we additionally confirmed these analyses with a Leave-one-out cross-validation procedure (shown in parentheses in Table 5).

Despite the comparatively small group sizes for inter-group comparisons with $\mathrm{fMRI}$ (i.e., 42 GER vs. 18 FR), we compared the Related > Unrelated contrasts between the GER and FR subgroups during (i) Encoding, (ii) Picture-Recognition, and (iii) Picture-word recognition. None of these comparisons revealed statistically significant modulation of activity by stimulus language.

In summary, we found no statistically significant evidence that the stimulus language modulated the semantic effects in our paradigm.

\section{Table 5. Language effect on behavior, GLM models outcomes}

\begin{tabular}{|c|c|c|c|}
\hline \multicolumn{4}{|l|}{ Encoding } \\
\hline & Chosen language & Related vs. Unrelated & Interaction \\
\hline $\begin{array}{c}\text { Response time } \\
\text { (LOO) }\end{array}$ & $\begin{array}{c}\beta=1551, \mathrm{SE}=1185, \\
p=0.1931 \\
(p=0.0698 \pm 0.0225)\end{array}$ & $\begin{array}{c}\beta=-1256, \mathrm{SE}=918 \\
p=0.1739 \\
(p=0.1417 \pm 0.0317)\end{array}$ & $\begin{array}{c}\beta=1.1, \mathrm{SE}=1676, \\
p=0.9995 \\
(p=0.9463 \pm 0.0864)\end{array}$ \\
\hline \multicolumn{4}{|c|}{ Picture recognition } \\
\hline $\begin{array}{c}\text { Accuracy } \\
\text { (LOO) }\end{array}$ & $\begin{array}{c}\beta=-1.9, \mathrm{SE}=3.0, \\
p=0.5242 \\
(p=0.4664 \pm 0.0682)\end{array}$ & $\begin{array}{c}\beta=9.5, \mathrm{SE}=2.3 \\
p<0.0001 \\
(p=0.00001 \pm 5.7 \mathrm{E}-6)\end{array}$ & $\begin{array}{c}\beta=0.7, \mathrm{SE}=4.3 \\
p=0.8691 \\
(p=0.8626 \pm 0.0711)\end{array}$ \\
\hline $\begin{array}{c}\text { Response time } \\
\text { (LOO) }\end{array}$ & $\begin{array}{c}\beta=443, \mathrm{SE}=575, \\
p=0.4432 \\
(p=0.4992 \pm 0.0687)\end{array}$ & $\begin{array}{c}\beta=-1577, \mathrm{SE}=445 \\
p=0.0006 \\
(p<0.00004 \pm 0.00001)\end{array}$ & $\begin{array}{c}\beta=-328, \text { SE }=813, \\
p=0.6871 \\
(p=0.6877 \pm 0.0677)\end{array}$ \\
\hline \multicolumn{4}{|c|}{ Picture-word recognition } \\
\hline $\begin{array}{c}\text { Accuracy } \\
\text { (LOO) } \\
\end{array}$ & $\begin{array}{c}\beta=-4.0, \mathrm{SE}=4.4, \\
p=0.3591 \\
(p=0.1394 \pm 0.0254)\end{array}$ & $\begin{array}{c}\beta=24.7, \mathrm{SE}=3.4 \\
p<0.0001 \\
(p=4.0 \mathrm{E}-12 \pm 2.2 \mathrm{E}-12)\end{array}$ & $\begin{array}{c}\beta=-1.2, S E=6.2, \\
p=0.8422 \\
(p=0.8408 \pm 0.0681)\end{array}$ \\
\hline $\begin{array}{c}\text { Response time } \\
\text { (LOO) }\end{array}$ & $\begin{array}{c}\beta=2912, \mathrm{SE}=1704, \\
p=0.0903 \\
(p=0.0462 \pm 0.0121)\end{array}$ & $\begin{array}{c}\beta=-8291, \mathrm{SE}=1323 \\
p<0.0001 \\
(p=1.0 \mathrm{E}-10 \pm 5.6 \mathrm{E}-11)\end{array}$ & $\begin{array}{c}\beta=-876, S E=2430, \\
p=0.7191 \\
(p=0.7205 \pm 0.0749)\end{array}$ \\
\hline
\end{tabular}

$\beta$, SE (standard error) and $p$-values obtained with GLM model explaining for the 3 sessions (Encoding, Picture recognition and Picture-word recognition), response time and accuracy, by language chosen as well as specificity of the stimuli (either "related" or "unrelated"). Between brackets are mentioned the corresponding final result (mean p-value \pm standard deviation) of the 120 GLM replicates from the leave-one-out (LOO) procedure). 
bioRxiv preprint doi: https://doi.org/10.1101/2021.09.07.459272; this version posted September 8, 2021. The copyright holder for this preprint (which was not certified by peer review) is the author/funder, who has granted bioRxiv a license to display the preprint in perpetuity. It is made available under aCC-BY-NC 4.0 International license.

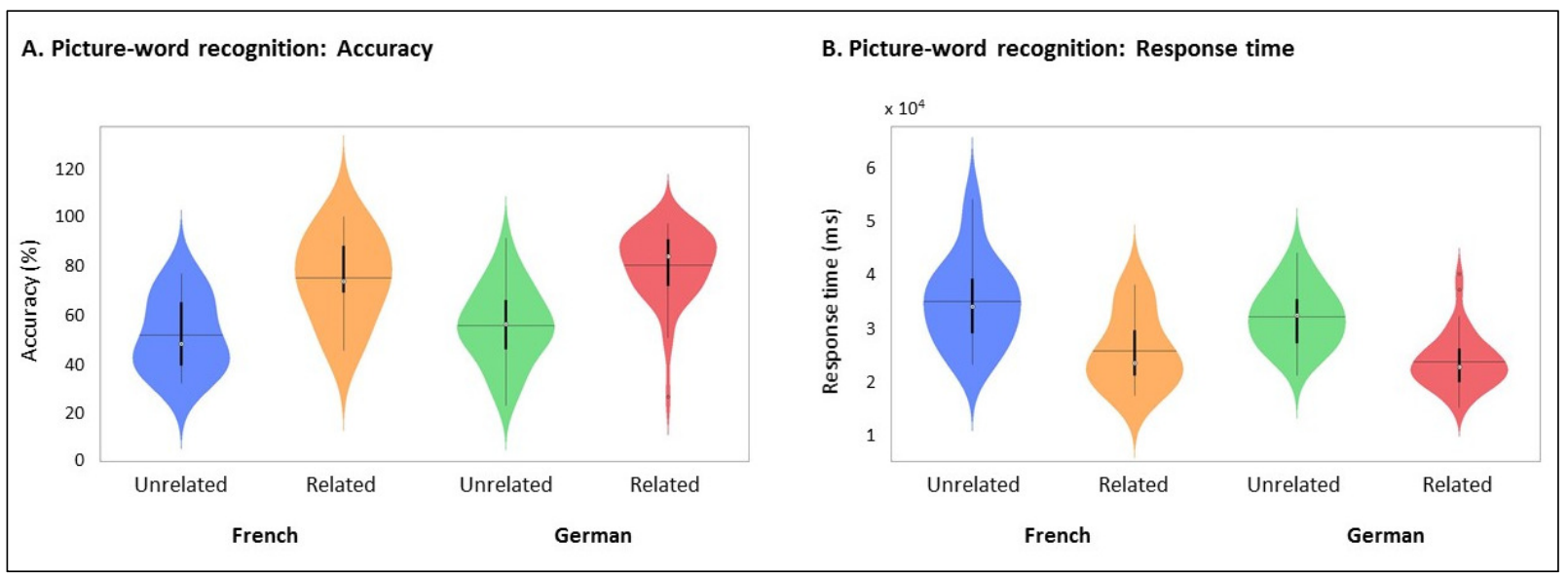

Figure 8. Semantic effect on behavior according to the language chosen during the task

A \& B: Inside the box plot, the bars represent the median, and the "circles" or "plusses" $\left({ }^{\circ}\right.$ or $\left.{ }^{+}\right)$represent the mean. A: for language effect (stimuli in French vs stimuli in German when related, and when unrelated) $p=0.3591$; for relationship effect $p<0.0001$ ); for interaction effect $p=0.8422$ ). B: for language effect (stimuli in French vs stimuli in German when related, and when unrelated) $p=0.0903$; for relationship effect $p<0.0001$ ); for interaction effect $p=0.7191)$. 


\section{Discussion}

In the present proof-of-principle study, we present a paradigm to test contextual semantic and object memory that can be performed in different participant-chosen languages. We here show that the paradigm activates distinct brain regions involved in object memory and semantic congruency judgments. There is also evidence for a powerful influence of semantic context on memory performance and memory-related neural activity. These semantic effects are equally present in subpopulations using different task languages (French and German). Based on these findings, the paradigm suggests a suitability for contextual memory studies in populations with different languages.

\section{Effect of semantic processing on memory encoding}

Our paradigm is based on the PWI phenomenon, where the RTs to name a presented object are slower when the distractor word describes a related than an unrelated object (La Heij, 1988; Starreveld \& La Heij, 2017). This RT increase is attributed to the increased difficulty in ignoring semantically related information. However, the RT effects in our study were not consistent with such a task difficulty related interpretation.

In the encoding stage of our experiment, the word was not a distractor to be ignored, and participants were instructed to pay attention to the picture and the word. The RTs were shorter for Related than for Unrelated judgments with these instructions (Figure 3A), unlike the PWI effect. If the RT is assumed to be an index of cognitive difficulty (M. Botvinick, Nystrom, Fissell, Carter, \& Cohen, 1999; M. M. Botvinick, Cohen, \& Carter, 2004), then Unrelated judgments should have evoked significantly more neural activity than the Related judgments. Specifically, increasing task difficulty has been shown to elicit more brain activity in the parietal, frontal, and cingulate cortices (including ACC, PFC) (Demb et al., 1995; Desai, Conant, Waldron, \& Binder, 2006; Gould, Brown, Owen, ffytche, \& Howard, 2003; Na, Bi, Tjan, Liu, \& Fang, 2018). However, in our study, neural activity for Related items was more significant than for Unrelated items across a widespread network of brain areas, including the bilateral angular gyrus, MTG, PCC, ACC, and PFC, thus speaking against task difficulty as the cause for activity changes (Table 1, Figure 3B).

Two lines of evidence suggest that the activity increases were associated with the effectiveness of memory encoding. During picture-recognition and picture-word recognition, Related items were recognized more rapidly and with greater accuracy than items judged to be Unrelated (Figure 4A, B \& Figure 6A, B). Also, during picture-recognition and picture-word recognition, Related items were associated with more significant neural activity relative to the Unrelated items over an extended neural network (Figure 4C, Table 2 \& Figure 6C, Table 3). Therefore, relatedness had a significant impact on memory encoding. This interpretation is in line with prior work demonstrating that increased activity during encoding and retrieval of 
associative memory is associated with better memory performance (Kukolja, Thiel, \& Fink, 2009; Kukolja, Thiel, Wilms, Mirzazade, \& Fink, 2009).

\section{Accounting for semantically-mediated recognition}

Our findings are consistent with prior studies that have consistently identified the ventral posterior parietal cortex (including the left angular gyrus and MCC/PCC) as having a role in memory processing, even though its functional role remains debated (Davey et al., 2016; Shimamura, 2011).

In light of these prior studies, our findings suggest a straightforward account of how the Related/Unrelated judgments during encoding might influence memory judgments in our task. In subjectively Related picture-word pairs, we assume that the participants could successfully identify a binding context between a picture and a word. However, when a picture-word pair was judged to be Unrelated, we assume that the search for a binding context was unsuccessful. The binding context is internally-generated information that was not contained directly in the stimuli but already present in semantic memory. During picture/picture-word recognition, the binding context facilitates access to encoded item representations. This is akin to the "semantic mediator effectiveness hypothesis" (Carpenter, 2009, 2011; Pyc \& Rawson, 2010), where the authors propose facilitation of memory retention when information mediating the association of a cue with a target is present. In our task, this semantically-mediated access might be absent for the Unrelated items. Due to these binding-context differences, Related items would therefore have a more substantial representation in memory than the Unrelated items and should, in turn, lead to faster retrieval and elicit higher neural activity.

Two lines of evidence support the above account. In the picture-word recognition task, the RTs for Related items were considerably shorter ( $800 \mathrm{~ms})$ than for Unrelated items. The $\mathrm{BC}$ hypothesis suggests an explanation for this substantial behavioral difference. In our task design, picture-word recognition was preceded by the picture-only recognition task, where a picture was presented in isolation. Despite being seen in isolation, when an Old Related picture is successfully recognized, the associated binding context might lead to the automatic retrieval of the paired word even though the task does not require it (also see (Carpenter, 2011)). Due to this automatic retrieval, the neural representations of these Related words might be more activated than for the Unrelated words. This difference in pre-activation might, in turn, affect performance in the subsequent picture-word recognition task. Specifically, it might facilitate more rapid access and recognition of the correct Related word from the four presented options than for the Unrelated words. In qualitative support of this possibility, during debriefing, $79 \%$ of the participants reported that they often remembered the word paired with the picture displayed in the picture (only)-recognition task. This was notable since $69 \%$ of the participants also reported that they did not use the Related/Unrelated judgments during encoding as a 
conscious strategy to remember the seen picture-word items. This observation is in line with recent work (Amer et al., 2020), which showed that co-occurring congruent, as well as noncongruent material (word and picture paired), are often bound together in memory in older adults.

Finally, the increased engagement of the left angular gyrus and the middle/posterior cingulate cortex (Figure 7) for Related > Unrelated items both during encoding and during recognition (i.e., picture-recognition and picture-word recognition) suggests that these regions are involved in representing the binding context information (as also suggested by (Shimamura, 2011).

\section{Semantic processes and language choice}

The influence of the language of the word stimuli on semantic processing and memory was a critical consideration of interest in the current study. Although language differences could theoretically lead to systematic cognitive differences (e.g., as postulated by the SapirWhorf hypothesis (Koerner, 1992)), we found no evidence for this in the behavioral and fMRI data. These findings strongly support the conclusion that individualizing the language materials of the task enables the inclusion of participants with different native languages. This is a crucial strength from a public health viewpoint when studying a multilingual population.

Language choice in the present study could theoretically be associated with education level. In Luxembourg, the language of instruction in primary school for all students is German and French. In secondary school, students chose either a technical path (instructed in German) or a general path (instructed in French). Since Luxembourg did not have a university until 2003 (https://wwwen.uni.lu/universite/presentation), students typically attended universities in neighboring countries to obtain an advanced degree (Germany, France, or Belgium, instructed in French). Therefore, a participant's preferred language might be an indirect proxy for socioeconomic and cultural factors as possible confounds. However, in the present study, neither the number of years of education nor neuropsychological test scores were significantly different between the two language sub-groups (Table 4).

An important topic for future research is whether differences in the relative proficiency in the multiple languages spoken by the multilingual participants are a predictor of differences in memory performance in our task and cognitive reserve.

\section{CONCLUSION}

We present a semantic contextual memory task that elicits robust behavioral and neural effects and is independent of the language used. These findings support the practical applicability of our paradigm for studying contextual memory in multilingual populations. A central guiding theme for this paradigm was to increase individualization and inclusivity, which are of 
significant public health relevance in heterogeneous populations. Having adapted and unbiased tools is of high relevance. It is even the basis of the concept of precision public health, where groups of populations are studied as units. A key priority for future research is to assess whether and how the level of multilingual capability modulates age-related changes to the neural systems implementing long-term memory. 


\section{Acknowledgments}

We thank Elke Bechholz, Anita Köth, Nadia Caldarelli for technical support during data acquisition, and the participants for their involvement.

\section{Funding}

This work was supported by the Luxembourg Institute of Health and the Research Centre Juelich. Additional funding by the Marga- and Walter Boll Foundation to GRF is gratefully acknowledged.

\section{References}

Abutalebi, J., Della Rosa, P. A., Green, D. W., Hernandez, M., Scifo, P., Keim, R., . . Costa, A. (2012). Bilingualism tunes the anterior cingulate cortex for conflict monitoring. Cereb Cortex, 22(9), 2076-2086. doi: 10.1093/cercor/bhr287

Aguirre, G. K. (2007). Continuous carry-over designs for fMRI. Neuroimage, 35(4), 14801494. doi: 10.1016/j.neuroimage.2007.02.005

Aguirre, G. K., Mattar, M. G., \& Magis-Weinberg, L. (2011). de Bruijn cycles for neural decoding. Neuroimage, 56(3), 1293-1300. doi: 10.1016/j.neuroimage.2011.02.005

Amer, T., Ngo, K. W. J., Weeks, J. C., \& Hasher, L. (2020). Spontaneous Distractor Reactivation With Age: Evidence for Bound Target-Distractor Representations in Memory. Psychol Sci, 31(10), 1315-1324. doi: 10.1177/0956797620951125

Andersson, J. L., Hutton, C., Ashburner, J., Turner, R., \& Friston, K. (2001). Modeling geometric deformations in EPI time series. Neuroimage, 13(5), 903-919. doi: 10.1006/nimg.2001.0746

Baldivia, B., Andrade, V. M., \& Bueno, O. F. A. (2008). Contribution of education, occupation and cognitively stimulating activities to the formation of cognitive reserve. Dement Neuropsychol, 2(3), 173-182. doi: 10.1590/S1980-57642009DN20300003

Bialystok, E., Craik, F. I., \& Freedman, M. (2007). Bilingualism as a protection against the onset of symptoms of dementia. Neuropsychologia, 45(2), 459-464. doi: 10.1016/j.neuropsychologia.2006.10.009

Bishop, C. (2006). Pattern Recognition and Machine Learning: New York: Springer.

Botvinick, M., Nystrom, L. E., Fissell, K., Carter, C. S., \& Cohen, J. D. (1999). Conflict monitoring versus selection-for-action in anterior cingulate cortex. Nature, 402(6758), 179-181. doi: 10.1038/46035

Botvinick, M. M., Cohen, J. D., \& Carter, C. S. (2004). Conflict monitoring and anterior cingulate cortex: an update. Trends Cogn Sci, 8(12), 539-546. doi: 10.1016/j.tics.2004.10.003

Brady, T. F., Konkle, T., Alvarez, G. A., \& Oliva, A. (2008). Visual long-term memory has a massive storage capacity for object details. Proc Natl Acad Sci U S A, 105(38), 14325-14329. doi: $10.1073 /$ pnas.0803390105

Brady, T. F., Konkle, T., Gill, J., Oliva, A., \& Alvarez, G. A. (2013). Visual long-term memory has the same limit on fidelity as visual working memory. Psychol Sci, 24(6), 981990. doi: $10.1177 / 0956797612465439$

Brodersen, K. H., Ong, C. S., Stephan, K. E., \& Buhmann, J. M. (2010). The balanced accuracy and its posterior distribution. . Paper presented at the 20th International Conference on Pattern Recognition. IEEE. 
Buracas, G. T., \& Boynton, G. M. (2002). Efficient design of event-related fMRI experiments using M-sequences. Neuroimage, 16 (3 Pt 1), 801-813.

Canini, M., Della Rosa, P. A., Catricala, E., Strijkers, K., Branzi, F. M., Costa, A., \& Abutalebi, J. (2016). Semantic interference and its control: A functional neuroimaging and connectivity study. Hum Brain Mapp, 37(11), 4179-4196. doi: 10.1002/hbm.23304

Carpenter, S. K. (2009). Cue strength as a moderator of the testing effect: the benefits of elaborative retrieval. J Exp Psychol Learn Mem Cogn, 35(6), 1563-1569. doi: $10.1037 / \mathrm{a} 0017021$

Carpenter, S. K. (2011). Semantic information activated during retrieval contributes to later retention: Support for the mediator effectiveness hypothesis of the testing effect. J Exp Psychol Learn Mem Cogn, 37(6), 1547-1552. doi: 10.1037/a0024140

Crafa, D., Hawco, C., \& Brodeur, M. B. (2017). Heightened Responses of the Parahippocampal and Retrosplenial Cortices during Contextualized Recognition of Congruent Objects. Front Behav Neurosci, 11, 232. doi: 10.3389/fnbeh.2017.00232

Dash, T., Berroir, P., Joanette, Y., \& Ansaldo, A. I. (2019). Alerting, Orienting, and Executive Control: The Effect of Bilingualism and Age on the Subcomponents of Attention. Front Neurol, 10, 1122. doi: 10.3389/fneur.2019.01122

Davey, J., Thompson, H. E., Hallam, G., Karapanagiotidis, T., Murphy, C., De Caso, I., . . . Jefferies, E. (2016). Exploring the role of the posterior middle temporal gyrus in semantic cognition: Integration of anterior temporal lobe with executive processes. Neuroimage, 137, 165-177. doi: 10.1016/j.neuroimage.2016.05.051

Demb, J. B., Desmond, J. E., Wagner, A. D., Vaidya, C. J., Glover, G. H., \& Gabrieli, J. D. (1995). Semantic encoding and retrieval in the left inferior prefrontal cortex: a functional MRI study of task difficulty and process specificity. J Neurosci, 15(9), 5870-5878.

Desai, R., Conant, L. L., Waldron, E., \& Binder, J. R. (2006). FMRI of past tense processing: the effects of phonological complexity and task difficulty. J Cogn Neurosci, 18(2), 278-297. doi: 10.1162/089892906775783633

Ehri, L. C., \& Ryan, E. B. (1980). Performance of bilinguals in a picture-word interference task. J Psycholinguist Res, 9(3), 285-302. doi: 10.1007/bf01067243

Eickhoff, S. B., Stephan, K. E., Mohlberg, H., Grefkes, C., Fink, G. R., Amunts, K., \& Zilles, K. (2005). A new SPM toolbox for combining probabilistic cytoarchitectonic maps and functional imaging data. Neuroimage, 25(4), 1325-1335. doi: 10.1016/j.neuroimage.2004.12.034

Flegal, K. E., Marin-Gutierrez, A., Ragland, J. D., \& Ranganath, C. (2014). Brain mechanisms of successful recognition through retrieval of semantic context. J Cogn Neurosci, 26(8), 1694-1704. doi: 10.1162/jocn_a_00587

Folstein, M. F., Robins, L. N., \& Helzer, J. E. . (1983). The mini-mental state examination. Archives of general psychiatry, 40(7), 812-812.

Friesen, D. C., Chung-Fat-Yim, A., \& Bialystok, E. (2016). Lexical selection differences between monolingual and bilingual listeners. Brain Lang, 152, 1-13. doi: 10.1016/j.bandl.2015.11.001

Gould, R. L., Brown, R. G., Owen, A. M., ffytche, D. H., \& Howard, R. J. (2003). fMRI BOLD response to increasing task difficulty during successful paired associates learning. Neuroimage, 20(2), 1006-1019. doi: 10.1016/S1053-8119(03)00365-3

Koerner, E. F. K. (1992). The Sapir - Whorf Hypothesis: A Preliminary History and a Bibliographical Essay. [Journal Article ]. Journal of Linguistic Anthropology, 2(2), 173-198. doi: doi-org.proxy.bnl.lu/10.1525/jlin.1992.2.2.173 
Konkle, T., Brady, T. F., Alvarez, G. A., \& Oliva, A. (2010). Conceptual distinctiveness supports detailed visual long-term memory for real-world objects. J Exp Psychol Gen, 139(3), 558-578. doi: 10.1037/a0019165

Kousaie, S., \& Phillips, N. A. (2012). Conflict monitoring and resolution: are two languages better than one? Evidence from reaction time and event-related brain potentials. Brain Res, 1446, 71-90. doi: 10.1016/j.brainres.2012.01.052

Kukolja, J., Goreci, D. Y., Onur, O. A., Riedl, V., \& Fink, G. R. (2016). Resting-state fMRI evidence for early episodic memory consolidation: effects of age. Neurobiol Aging, 45, 197-211. doi: 10.1016/j.neurobiolaging.2016.06.004

Kukolja, J., Thiel, C. M., \& Fink, G. R. (2009). Cholinergic stimulation enhances neural activity associated with encoding but reduces neural activity associated with retrieval in humans. $J$ Neurosci, 29(25), 8119-8128. doi: 10.1523/JNEUROSCI.0203-09.2009

Kukolja, J., Thiel, C. M., Wilms, M., Mirzazade, S., \& Fink, G. R. (2009). Ageing-related changes of neural activity associated with spatial contextual memory. Neurobiol Aging, 30(4), 630-645. doi: 10.1016/j.neurobiolaging.2007.08.015

La Heij, W. (1988). Components of Stroop-like interference in picture naming. Mem Cognit, 16(5), 400-410.

Li, X., Morgan, P. S., Ashburner, J., Smith, J., \& Rorden, C. (2016). The first step for neuroimaging data analysis: DICOM to NIfTI conversion. J Neurosci Methods, 264, 47-56. doi: 10.1016/j.jneumeth.2016.03.001

Liu, T. T., \& Frank, L. R. (2004). Efficiency, power, and entropy in event-related FMRI with multiple trial types. Part I: theory. Neuroimage, 21(1), 387-400.

Liu, T. T., Frank, L. R., Wong, E. C., \& Buxton, R. B. (2001). Detection power, estimation efficiency, and predictability in event-related fMRI. Neuroimage, 13(4), 759-773. doi: 10.1006/nimg.2000.0728

Na, R., Bi, T., Tjan, B. S., Liu, Z., \& Fang, F. (2018). Effect of task difficulty on blood-oxygenlevel-dependent signal: A functional magnetic resonance imaging study in a motion discrimination task. PLoS One, 13(6), e0199440. doi: 10.1371/journal.pone.0199440

Nichols, T., Brett, M., Andersson, J., Wager, T., \& Poline, J. B. (2005). Valid conjunction inference with the minimum statistic. Neuroimage, 25(3), 653-660. doi: 10.1016/j.neuroimage.2004.12.005

Nichols, T. E., Das, S., Eickhoff, S. B., Evans, A. C., Glatard, T., Hanke, M., .. Yeo, B. T. (2016). Best Practices in Data Analysis and Sharing in Neuroimaging using MRI. bioRxiv. doi: 10.1101/054262

Packard, P. A., Rodriguez-Fornells, A., Bunzeck, N., Nicolas, B., de Diego-Balaguer, R., \& Fuentemilla, L. (2017). Semantic Congruence Accelerates the Onset of the Neural Signals of Successful Memory Encoding. J Neurosci, 37(2), 291-301. doi: 10.1523/JNEUROSCI.1622-16.2016

Perquin, M., Vaillant, M., Schuller, A. M., Pastore, J., Dartigues, J. F., Lair, M. L., . . MemoVie, G. (2013). Lifelong exposure to multilingualism: new evidence to support cognitive reserve hypothesis. PLoS One, 8(4), e62030. doi: 10.1371/journal.pone.0062030

Power, J. D., Barnes, K. A., Snyder, A. Z., Schlaggar, B. L., \& Petersen, S. E. (2012). Spurious but systematic correlations in functional connectivity MRI networks arise from subject motion. Neuroimage, 59(3), 2142-2154. doi: 10.1016/j.neuroimage.2011.10.018

Pyc, M. A., \& Rawson, K. A. (2010). Why testing improves memory: mediator effectiveness hypothesis. Science, 330(6002), 335. doi: 10.1126/science.1191465 
Ratcliff, R. (1993). Methods for dealing with reaction time outliers. Psychol Bull, 114(3), 510-532.

Rosinski, R. R. (1977). Picture-Word Interference Is Semantically Based. Child Development, 48(2), 643-647.

Rossion, B., \& Pourtois, G. (2004). Revisiting Snodgrass and Vanderwart's object pictorial set: the role of surface detail in basic-level object recognition. Perception, 33(2), 217-236. doi: 10.1068/p5117

Shimamura, A. P. (2011). Episodic retrieval and the cortical binding of relational activity. Cogn Affect Behav Neurosci, 11(3), 277-291. doi: 10.3758/s13415-011-0031-4

Starreveld, P. A., \& La Heij, W. (2017). Picture-word interference is a Stroop effect: A theoretical analysis and new empirical findings. Psychon Bull Rev, 24(3), 721-733. doi: 10.3758/s13423-016-1167-6

Stroop, J. (1935). Studies of interference in serial verbal reactions. Journal of Experimental Psychology, 18, 643-662. doi: http://dx.doi.org/10.1037/h0054651

Wilcox, R. R., \& Keselman, H. J. (2003). Modern robust data analysis methods: measures of central tendency. Psychol Methods, 8(3), 254-274. doi: 10.1037/1082989x.8.3.254

Williams, B. D., Pendleton, N., \& Chandola, T. (2020). Cognitively stimulating activities and risk of probable dementia or cognitive impairment in the English Longitudinal Study of Ageing. SSM Popul Health, 12, 100656. doi: 10.1016/j.ssmph.2020.100656 Zandt, T. V. (2002). Analysis of response time distributions. 